\title{
Cataract: refractive error, diabetes, and morphology
}

\author{
E. S. PERKINS
}

From the Department of Ophthalmology, University of Iowa Hospitals and Clinics, Iowa City, USA

SUMMARY A retrospective analysis of 388 records of patients undergoing surgery for cataract between the years 1968 and 1978 showed that more women than men were admitted. About $13 \cdot 7 \%$ of the patients were diabetic, and there was a striking excess of women over men with diabetes and cataract. The diabetic patients required surgery at an earlier age than the non-diabetics. Patients who had been refracted at least 5 years before surgery showed an incidence of myopia of $-1.00 \mathrm{D}$ or more of $25 \cdot 4 \%$. In $34 \%$ of the whole series the aphakic refraction was less than $+11 \cdot 00 \mathrm{D}$, again suggesting that myopes are more likely to develop a cataract than non-myopes. Posterior subcapsular lens changes alone or in combination with nuclear or cortical opacities were present in over $40 \%$ of all patients and the mean age of patients with this type of change alone was significantly lower than patients with predominantly nuclear or cortical changes. Posterior subcapsular opacities seem to be more common in Iowa than in England or India. The morphological similarity of this type of lens change with known types of secondary cataract suggests that it is not entirely a senile change but may be due to environmental or dietetic factors.

There is some evidence ${ }^{12}$ that cataract occurs more frequently in myopes than non-myopes, so in order to investigate this further I analysed the hospital records of patients over the age of 50 who had had cataract surgery at The University of Iowa over a 10 year period with particular reference to the pre- and postoperative refraction. A note was also made of the type of cataract present and whether the patient was diabetic.

Patients with known open angle ( 38 cases) or closed angle glaucoma (22 cases) were excluded, as both these conditions are associated with specific refractive errors, myopia in the case of open angle glaucoma, and hypermetropia in closed angle glaucoma. Traumatic cataracts or those occurring after ocular surgery (for example, for retinal detachment) were also excluded. The analysis was also confined to patients who had attended the University Hospital at least 5 years prior to the date of surgery, as it was hoped by this means to obtain a high proportion of patients who had been refracted 5 years before surgery, because after this period the lens changes themselves could produce a myopic refraction.'

Correspondence to Dr Perkins, C. S. O'Brien Library, Department of Ophthalmology, University of lowa Hospitals and Clinics, lowa City, Iowa 52242, USA

\section{Material and methods}

The clinical features of the lens changes were classified into 7 main types-nuclear sclerosis, posterior subcapsular cataract (PSC), cortical opacities, and combinations of 2 of these features. If the lens was completely opaque, it was classified as a mature cataract. In most cases the description was clear enough to make an accurate classification, but in the few cases described simply as senile cataract they were classed as mature. Only one eye of each patient was included. Refractions were recorded as the spherical equivalent of the spectacle prescription. Patients were included in the series only if satisfactory postoperative refractions were obtained. Preoperative refraction was the manifest refraction recorded at the patient's first visit to the eye department. In some cases the lens opacities made it impossible to do an accurate refraction, so that the patient's own spectacle correction was used.

Statistical methods. The significance of differences between means was derived from the standard error of the difference and use of a table. ${ }^{3}$ The difference between sex distributions was calculated by the $\chi^{2}$ test. 
Table 1 Age at operation and sex distribution of all patients

\begin{tabular}{lccccccr}
\hline & $50-59$ & $60-69$ & $70-79$ & $80-89$ & $90+$ & Total & $\%$ of total \\
\hline Male non-diabetics & 31 & 45 & 58 & 28 & 0 & 162 & $41 \cdot 7$ \\
Male diabetics & 1 & 5 & 1 & 0 & 0 & 7 & $1 \cdot 8$ \\
Total males & 32 & 50 & 59 & 28 & 0 & 169 & $43 \cdot 5$ \\
Female non-diabetic & 25 & 43 & 69 & 31 & 5 & 173 & $44 \cdot 6$ \\
Female diabetic & 8 & 19 & 14 & 5 & 0 & 46 & $11 \cdot 9$ \\
Total females & 33 & 62 & 83 & 36 & 5 & 56.5 \\
All cases & 65 & 112 & 142 & 64 & 5 & 388 & 100 \\
Percentage distribution & $16 \cdot 8$ & $28 \cdot 9$ & $36 \cdot 6$ & $16 \cdot 4$ & $1 \cdot 3$ & 100 & \\
\hline
\end{tabular}

\section{Results}

AGE AND SEX

A total of 388 records were included in the analysis; 169 were men and 219 women. The age and sex structure of this population is shown in Table 1. The age given is the age at which cataract extraction was done. It will be seen that women outnumber men in this population, but the disparity decreases if patients with diabetes are excluded. There were 53 diabetics $(13.7 \%), 46$ women and 7 men (Table 2), leaving 162 men $(41 \cdot 7 \%)$ and 173 women $(44.6 \%)$ non-diabetics. The ratio of men to women in these age groups in the populations of Iowa is men $45 \cdot 3 \%$, women $54 \cdot 6 \%$.

The mean ages of the diabetic and non-diabetic patients is shown in Table 1. The mean age of both male and female diabetics was lower than that of the non-diabetics, and the difference between the males was significant at the $1 \%$ level $(p<0.01)$ and in the females at the $5 \%$ level. The difference in sex distribution between the diabetics and non-diabetics was highly significant $\left(\chi^{2}=22 \cdot 99, \mathrm{p}<0 \cdot 001\right)$.

\section{REFRACTION}

Unfortunately only 67 patients had had a refraction 5 years or more before surgery. There were 17 patients with a myopic refraction (spherical equivalent) of $-1 \cdot 0 \mathrm{D}$ or more $(25.4 \%)$, and 10 with refractions greater than $-2.0 \mathrm{D}(14.9 \%)$. The distribution of preoperative aphakic refractions for the whole series is shown in Table 3 . In $34 \%$ the aphakic refraction was less than $+11.00 \mathrm{D}$ and $20.6 \%$ had an aphakic refraction of less than $+10 \cdot 50 \mathrm{D}$. The mean age of the latter was $70 \cdot 1(\mathrm{SD} 9 \cdot 95)$ years.

\section{TYPE OF CATARACT}

The percentage distribution of the 7 types of cataract in the diabetics and non-diabetics is shown in Table 4. There is no significant difference between the distribution among diabetics. Posterior subcapsular changes were the main type of opacity in $11 \%$ of non-diabetics and $11.3 \%$ of diabetics, and were present in $44.9 \%$ of non-diabetics and $43.6 \%$ of diabetics. If the patients with mature cataracts are excluded, posterior subcapsular changes (types 2, 4, and 6) were present in $60.9 \%$ and were the predominant finding in $15 \cdot 1 \%$.

The mean ages of the patients with types 1,2 , and 3 lens changes is shown in Table 5 . There is a highly significant difference in the mean age of those with PSC, those with nuclear sclerosis, and those with cortical changes. There was no significant difference in the distribution of lens types among myopes, emmetropes, and hyperopes.

Only 2 patients with PSC alone were reported to have been receiving long-term corticosteroid therapy,

Table 2 Mean age of diabetic and non-diabetic patients

\begin{tabular}{lrlll}
\hline Sex & No. & Diabetic & No. & Non-diabetic \\
\hline M & 7 & $64 \cdot 6 \pm 3 \cdot 87$ & 162 & $69 \cdot 8 \pm 9 \cdot 39$ \\
F & 46 & $67 \cdot 7 \pm 8 \cdot 18$ & 173 & $71 \cdot 3 \pm 11 \cdot 21$ \\
\hline
\end{tabular}

Statistical significance of differences: males $0 \cdot(0) 2<p<0) \cdot(01$, females ().(0) $1<\mathrm{p}<0 \cdot(0)$.

Table 3 Refractions of cataract patients (spherical equivalents)

\begin{tabular}{lcc}
\hline Refraction & No. & Percentage \\
\hline 5 years prior to surgery & & \\
Myopia (>-1.0 D) & 17 & $25 \cdot 4$ \\
Emmetropia (-().9 D to + ().9 D) & 22 & $32 \cdot 8$ \\
Hypermetropia (>+1.() D) & 28 & $41 \cdot 8$ \\
Total & 67 & 100 \\
Postoperative & & \\
<+11.0 D & 132 & $34 \cdot 0$ \\
+11.0 Dor morc & 256 & $66 \cdot 0$ \\
Total & 388 & 100 \\
\hline
\end{tabular}

Table 4 Percentage distribution of types of cataract

\begin{tabular}{|c|c|c|c|}
\hline & & Non-diabetic & Diabetic \\
\hline 1 & Nuclear sclerosis & $13 \cdot 7$ & $7 \cdot 5$ \\
\hline 2 & Posterior subcapsular plaque & $11 \cdot 0$ & $11 \cdot 3$ \\
\hline 3 & Cortical & $6 \cdot()$ & $5 \cdot 7$ \\
\hline 4 & 1 and 2 & $20 \cdot 0$ & $24 \cdot 5$ \\
\hline 5 & 1 and 3 & $9 \cdot 0$ & $15 \cdot 1$ \\
\hline 6 & 2 and 3 & 13.7 & $7 \cdot 5$ \\
\hline 7 & Mature cataract & $26 \cdot 6$ & $28 \cdot 3$ \\
\hline
\end{tabular}


Table 5 Mean age of patients with nuclear, posterior subcapsular, and cortical lens changes

\begin{tabular}{lll}
\hline Type of opacity & No. & Mean age \\
\hline 1 Nuclear sclerosis & 50 & $70 \cdot 7 \pm 9 \cdot 11$ \\
2 Postcrior subcapsular & 43 & $62 \cdot 3 \pm 8 \cdot 75^{*}$ \\
3 Cortical & 23 & $71 \cdot 4 \pm 6 \cdot 83$ \\
\hline
\end{tabular}

${ }^{*}$ Significantly different from 1 and $3, p<0.001$.

one for pemphigus and one for rheumatoid arthritis. One patient with type 4 lens changes had also been on systemic steroids for arthritis. It is possible that other patients had previously received steroid therapy that was not recorded in the eye notes.

\section{DIABETES AND CATARACT}

The incidence of diabetes in this cataract series was $13.66 \%$. The high ratio of women to men (over $6 / 1$ ) in the diabetics was particularly striking, and the age at which surgery was performed was significantly lower in both men and women than in the non-diabetics.

There was no significant difference in the clinical type of cataract between the diabetics and nondiabetics.

\section{Discussion}

The age at which a patient decides to have a cataract extraction will depend on the visual requirements of the individual and a variety of social factors, so that it is not possible to derive useful statistics concerning the prevalence of cataract from a retrospective survey such as this. It is perhaps surprising to find that $16 \%$ of patients with so-called senile cataract were under the age of 60 , but $2.7 \%$ of the population aged 50 to 64 in the Framingham survey and $4.9 \%$ in the Health and Nutrition Examination survey were found to have significant cataract or were aphakic. ${ }^{3}$ A prominent factor influencing the timing of operation is the vision requirements for renewal of driving licences and in Iowa a vision of $20 / 40$ or better in one eye is required, so that patients may elect to have surgery at an earlier stage of cataract than in countries with less stringent visual requirements or in populations less reliant on automobiles.

Table 6 Percentage of diabetics having a cataract operation in England and lowa

\begin{tabular}{lcccccc}
\hline & \multicolumn{3}{c}{ England (1930) } & & \multicolumn{2}{l}{ Iowa (1970) } \\
\cline { 2 - 3 } \cline { 6 - 7 } \cline { 6 - 7 } & Male & Female & & & Male & Female \\
\hline Total paticnts & 386 & 638 & & & 169 & 219 \\
Diabctics & 27 & 86 & & 7 & 46 \\
Percentage diabetics & 6.99 & 13.48 & & & 4.14 & 21.00 \\
\hline
\end{tabular}

The sex ratio of the cataract patients was similar to that of the population of Iowa, and, as other surveys ${ }^{45}$ have shown, more women than men have cataract operations. There was, however, a surprising excess of women over men (6/1) with diabetes and cataract, even though diabetes is known to occur more frequently in women. Caird et al..$^{5}$ also found that more diabetic women (3/1) than men had operations for cataract. The total percentage of cataract patients with diabetes $(13.0 \%)$ in their series from Oxford, England, is very close to the figure of $13.7 \%$ for Iowa (Table 6). The percentage of the population with lens changes and diabetes in the Framingham study was $8.2 \%$ for the age group 50 to 64 years, $11.6 \%$ for the 65 to 74 year-olds, and $13 \%$ for patients of 75 to 85 . Ederer et al. ${ }^{3}$ showed conclusively from an analysis of 2 population surveys that diabetics have an increased risk of developing cataract, a conclusion supported by the figures from Iowa which also confirm previous studies that diabetics have cataract operations at an earlier age than non-diabetics.

It was disappointing that records of refractions 5 years or more prior to surgery (to avoid the effect of myopia due to the lens changes themselves) were available only for $17 \%$ of the patients, but the aphakic refraction was available in all cases. Theoretically an emmetropic eye with an axial length of $23.9 \mathrm{~mm}$ requires a spherical correcting lens of $+11.43 \mathrm{D} .^{6} \mathrm{As}$ most patients have some degree of additional astigmatic error, the spherical equivalent of the aphakic correction for an emmetropic eye would be approximately $+12.00 \mathrm{D}$. A spherical equivalent of $+11.00 \mathrm{D}$ suggests that the eye was $-1.75 \mathrm{D}$ myopic before surgery. If this is so the present finding of an aphakic correction of less than $+11.00 \mathrm{D}$ in $34 \%$ of patients agrees well with Weale's' estimate of $35 \%$ of myopes and Hoffer's ${ }^{2}$ estimate based on axial length of $33 \%$ of myopia in eyes having cataract extraction.

Unfortunately there are no figures for the prevalence of myopia in Iowa. Figures are available for a national probability sample derived from the National Health and Nutrition Examination Survey ${ }^{7}$ for persons between the ages of 12 and 54 in the United States. The prevalence of any degree of myopia in this sample was $25 \%$, with $9 \%$ having refractions of $-2.00 \mathrm{D}$ or more. In the present series of 67 patients with preoperative refractions myopia of any degree was found in $37 \%$ and $14.9 \%$ had errors of $-2.00 \mathrm{D}$ or more. The aphakic refraction-suggested significant myopia in $34 \%$ of eyes, so that the incidence of myopia seems to be greater than would be expected in a normal population. However, the national probability sample showed such wide variations with such factors as race, family income, and years of schooling that comparisons without taking these factors into account have to be accepted with caution. 
There was no significant difference in the distribution of the types of cataract between the myopes and non-myopes, so that although myopia predisposes to cataract it was not associated with a clinically distinct type of lens opacity in this series.

In highly myopic eyes cataract usually presents as posterior subcapsular changes. This type of cataract was slightly more common in the myopes, but the difference was not statistically significant, probably because there were not many high myopes in this series.

Over $10 \%$ of the charts examined were rejected from analysis because of the diagnosis of glaucoma in addition to cataract. As this incidence is considerably higher than that of a general population, glaucoma seems to be an aetiological factor. This may be partly because of the cataractogenic effect of long-term miotic treatment and partly due to the development of cataract following glaucoma surgery.

The analysis of the types of cataract was done because I had been impressed with the high proportion of patients in Iowa with 'senile' cataract who had posterior subcapsular plaques compared with similar patients in England.

Posterior cortical or cupuliform lens changes are relatively uncommon as the main change in England. Foster and Benson ${ }^{8}$ found only $6 \%$ in a series of 154 cases, and in Kirby's" series in the US there were $3.5 \%$ and a further $4 \%$ combined with nuclear changes and $2.5 \%$ combined with cortical changes. Kirby ${ }^{11}$ found $7 \%$ of posterior cortical opacities in a series of diabetics with cataract. Posterior subcapsular changes are rare $(1.8 \%)$ in the Punjab according to a detailed study in 1976-7, "1 and were not reported at all in 116 cases in Australian Aboriginals. ${ }^{12}$ In the present series $11 \%$ had mainly posterior subcapsular changes, but such changes were present in $44 \%$ of all cataracts. These percentages increase to $15 \%$ and $61 \%$ if patients with mature cataracts are excluded.

Others have questioned whether posterior subcapsular lens changes should be considered as senile changes, and this type of opacity is strongly associated with many known types of secondary cataract. The fact that the mean age of patients with this type of cataract is lower than that of patients with other types lends support to the possibility that some environmental factor is involved. Morphologically this type of opacity is similar to that seen as a result of irradiation or corticosteroid therapy, ${ }^{1314}$ but there was no evidence that medically prescribed corticosteroids were responsible for more than one or 2 cases.

As far as radiation is concerned none of the patients in this series had received radiation treatment to the eye or orbit. However, on comparing the hospital numbers with those on the tumour registry it was found that 52 patients $(13.4 \%$ of the total) had received treatment for non-ocular tumours. Twentynine $(60 \%)$ of these patients had posterior subcapsular opacities either as the main change (8 patients) or in combination with nuclear or cortical changes. This is not significantly different from the distribution in patients not on the tumour registry. Natural irradiation from sunlight has been implicated in the causation of brunescent cataracts ${ }^{15}$ but not with posterior subcapsular opacities.

Drew $^{16}$ has suggested that alcoholism is a factor in producing PSC, and Sabiston ${ }^{17}$ described an association between alcoholism, Dupuytren's contracture, and cataract, but other dietetic factors may be involved. My impression is that a typical North American diet contains greater quantities of meat, dairy products, and poultry than is found in a British diet, and although it seems unlikely that such foods are responsible in themselves it is just possible that additives in animal feed or in processing of meat could have an effect over many years. For example, the veterinary antibiotic and antihelminithic drug hygromycin B is known to be capable of inducing posterior cortical subcapsular cataracts in pigs morphologically similar to human senile posterior cortical subcapsular cataracts. ${ }^{18}$ As Hockwin and Koch $^{19}$ have suggested, a variety of minor injuries may combine to have cataractogenic effects, and it is possible that several factors each insufficient in itself may have an additive effect. Whatever the aetiology of PSC the evidence suggests that this type of cataract is rare in India, was uncommon in England and the USA in the 1930s, but is now relatively common in Iowa. A prospective study with careful attention to dietary habits might help to explain this problem.

\section{References}

1 Weale RA. A note on the possible relation between refraction and a disposition for senile cataract. Br J Ophthalmol 1980; 64: 311-4.

2 Hoffer KJ. Biometry of 7,500 cataractous cyes. Am J Ophthalmol 1980; 90: 360)-8.

3 Edener F, Hiller MS. Senile lens changes and diabetes in two populations studics. Am J Ophthalmol 1981; 91: 381-95.

4 Kini MM, Lcibowitz HM, Colton T, Nickerson RJ, Ganley J, Dawber TR. Prevalence of senile cataract, diabetic retinopathy, senile macular degeneration and open angle glaucoma in the Framingham Eyc Study. Am J Ophthalmol 1978; 85: 28-34.

5 Caird FI, Hutchinson M. Piric A. Cataract and diabetes. Br Med J 1964; ii: 665 .

6 Donders FC. On the anomalies of accommodation and refraction of the eye. London: New Sydenham Socicty, 1864.

7 Sperduto RD, Scigel D, Roberts J, Rowland M. Arch Ophthalmol 1983; 101: 405-7.

8 Foster J, Benson J. Discases of the Iens 1. The percentage incidence and surgical significance of different forms of senile cataract. Trans Ophthalmol Soc UK 1934; 54: 127-36.

9 Kirby DB. Pathogenesis of senile cataract. Arch Ophthalmol 1932; 8: 96-119.

10) Kirby DB. Cataract and diabetes. Arch Ophthalmol 1933; 9: 966-73. 
11 Chatterjec A, Milton RC, Thyle S. Prevalence and actiology of cataract in Punjab. BrJ Ophthalmol 1982; 66: 35-42.

12 Taylor HR. The environment and the lens. Br J Ophthalmol 1980; 64: 303-10.

13 Strecten BW, Eshaghian J. Human postcrior subcapsular cataract. Arch Ophthalmol 1978; 96: 1653-8.

14 Grciner JV, Chylock LT. Posterior subcapsular cataracts: Histopathologic study of stcroid-associated cataracts. Arch Ophthalmol 1979; 97: 135-44.

15 Zigman S, Dátiles M, Torczynski E. Sunlight and human cataracts. Invest Ophthalmol Visual Sci 1979; 18: 462-7.
16 Drew RC. Ethanol cataract. Proceedings of the 21st international congress of ophthalmology, Mexico, 1970. Amsterdam: Excerpta Medica, 1971: part 2: 753-8.

17 Sabiston DW. Cataracts, Dupuytren's contracture and alcohol addiction. Am J Ophthalmol 1975; 76: 1005-7.

18 Creighton MO, Trevithick JR, Sanford SE, Dukes TW. Modelling cortical cataractogenesis. IV induction by Hygromycin B in vivo (swinc) and in vitro (rat lens). Exp Eye Res 1982; 34: 467-76.

19 Hockwin O, Koch HR. In: Bellows JG, ed. Cataract and anomalies of the lens. New York: Grune and Stratton, 1975: 243-54. 